5
5
5
5
5
5

WANL-TME-531

SEPTEMBER, 1963

MASTER

\title{
INTERIM REPORT ON ELECTRICALLY SIMULATED NUCLEAR TRANSIENTS
}

(Title Unclassified)

DISTRIBUTION DE IHIS DOCUMENT IS UNLUMTED

Astronuclear Laboratory

Westinghouse Electric Corporation

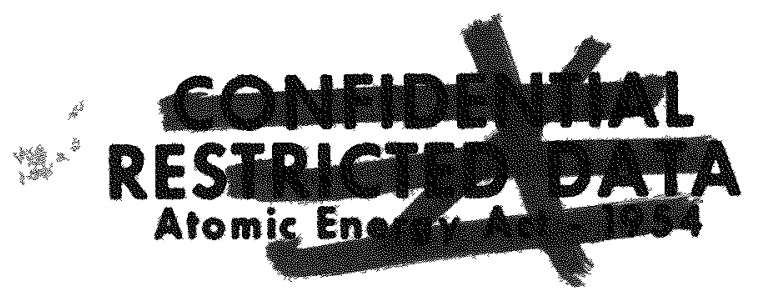




\section{DISCLAIMER}

This report was prepared as an account of work sponsored by an agency of the United States Government. Neither the United States Government nor any agency Thereof, nor any of their employees, makes any warranty, express or implied, or assumes any legal liability or responsibility for the accuracy, completeness, or usefulness of any information, apparatus, product, or process disclosed, or represents that its use would not infringe privately owned rights. Reference herein to any specific commercial product, process, or service by trade name, trademark, manufacturer, or otherwise does not necessarily constitute or imply its endorsement, recommendation, or favoring by the United States Government or any agency thereof. The views and opinions of authors expressed herein do not necessarily state or reflect those of the United States Government or any agency thereof. 


\section{DISCLAIMER}

Portions of this document may be illegible in electronic image products. Images are produced from the best available original document. 


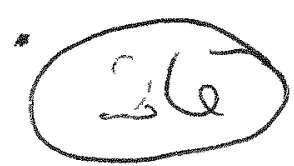

NOTICE.

This report was prepared as an account of work sponsored by the United States Government. Neither the United States nor the United States Energy Research and Development Administration, nor any of their employees, nor any of their contractors, subcontractors, or their employees, makes any warranty, express or implied, or assumes any legal liability or responsibility for the accuracy, completeness or usefulness of any information, apparatus, product or process disclosed, or represents that its use would not infringe privately owned rights.

\section{INTERIM REPORT ON ELECTRICALLY SIMULATED NUCLEAR TRANSIENTS}

(Title Unclassified)

\section{AUTHORS:}

C. A. Bodenschatz

C.A Eoredetis

J.A. Roll

$\Rightarrow 4 \cdot x+x$

G.T. Rymer

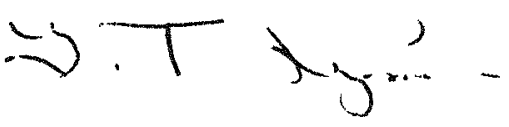

\section{APPROVED BY:}

W.H.Arnoldis.

W. H. Arnold, Jr.

Deputy Manager for Analysis

NERVA Engineering \& Development
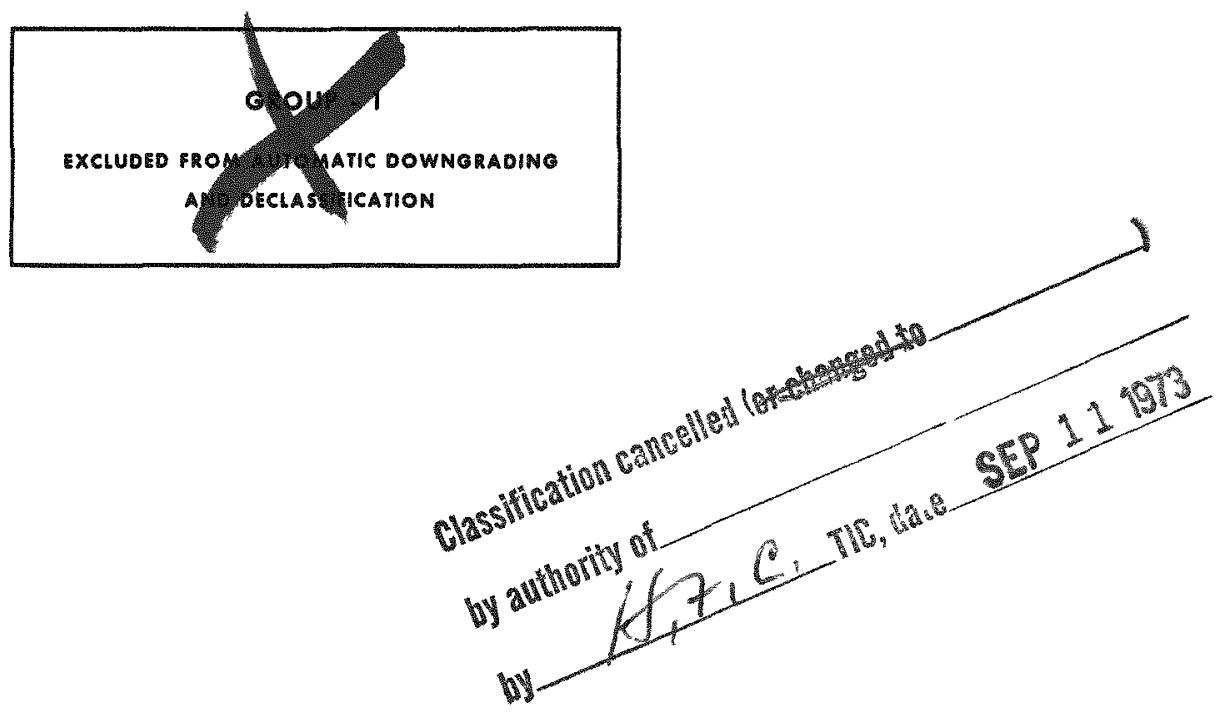

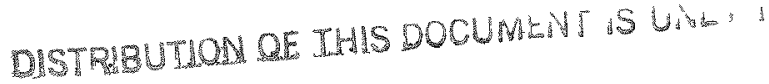

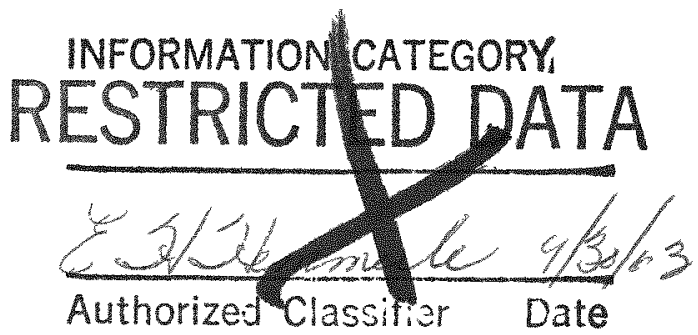

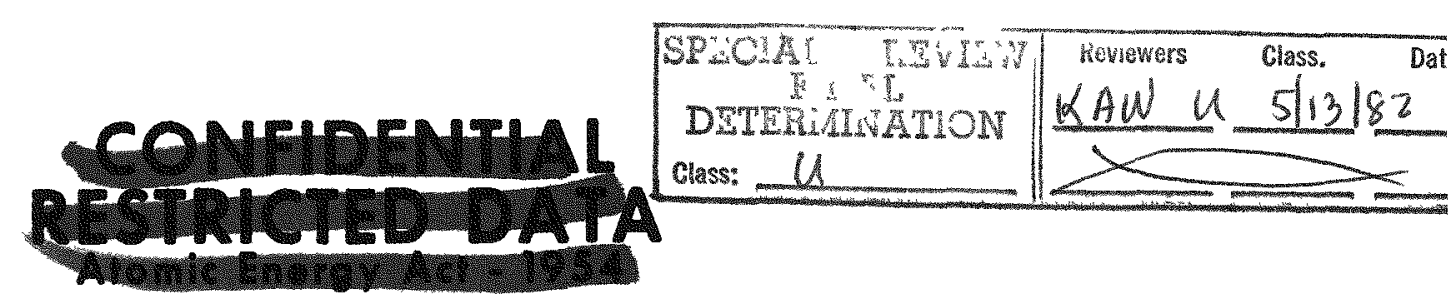


CONFIDENTIAL.

Atomic energy

(2) Istronuclear

WANL-TME -531

TABLE OF CONTENTS

1. Summary

11. Introduction

III. Description of Experiments

A. Experimental Equipment

B. Model Specification

C. Experimental Procedures

D. Reduction of Data

IV. Discussion of Results

A. Energy Losses

B. Effects of Energy Deposition

V. Conclusions and Future Plans

CONFIDENTIAL

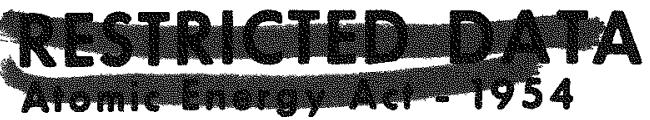

$-i-$ 


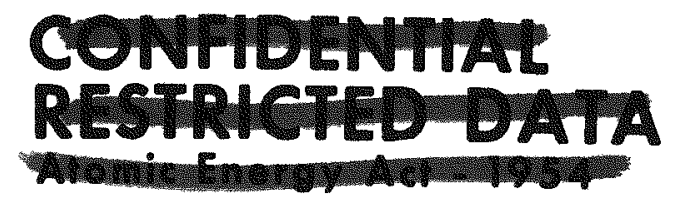

\section{LIST OF FIGURES}

Number

3

4 5

\begin{abstract}
Title
Sample Support and Electrode Assembly

Auxiliary Monitor Equipment for Transient Experiment

Circuitry for Energy Deposition in Transient Experiment

Oscilloscope Trace During Transient

Fragmentation of Graphite During 16 Millisecond Transient at $2000 \mathrm{cals} / \mathrm{gm}$
\end{abstract}

Page

4

8

9

13 


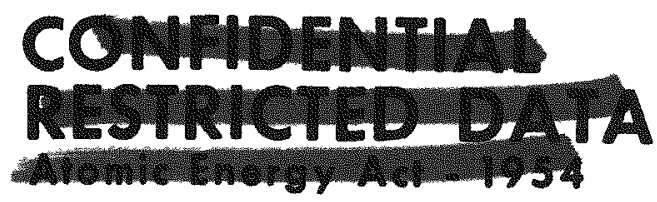

\section{SUMMARY}

$\therefore \quad$ The effects of nuclear transients on NERVA fuel are significant to the analys is of reactor excursions, to the feasibility of a nuclear destruct system, and to the physical limitations of reactor startup. A preliminary study was in itiated by LASL in 1960, employing an electrical simulation of nuclear transients. Later, a joint LASL, Argonne National Laboratory, WANL program was undertaken to study these effects in the TREAT reactor.

In view of the results and limitations of these programs, a series of high power, short transient, electrical heating. experiments was performed recently at WANL. This involved the resistance heating of 7.5 inch samples of unfueled NERVA geometry graphite for transients of 16 to 100 milliseconds duration. The results of these tests are shown in Table 1. The effective energies deposited into the samples ranged from 500 to 5600 cals/ gram. The energy required to cause fragmentation was between 1700 and 2000 cals/gram. Plans for future work have been formulated, 


\section{INTRODUCTION}

Studies of the effects of nuclear transients on NERVA core material are significant to the following programs:

\section{a. Reactor Excursion Analysis \\ b. Nuclear Destruct System \\ c. Start-up Limitations}

The analysis of reactor excursions is directly dependent upon the understanding of shutdown mechanisms as well as the physical integrity of the fuel element material subsequent to the excursion. The feasibility of a nuclear destruct system or combined chemical-nuclear destruct system for post-operational destruction of the core assembly is predicated on the behavior of the core material during fast nuclear transients. Conversely, the stability of NERVA fuel element material during engine start-up can be partially investigated from slow nuclear transient tests.

Experiments on the behavior of ROVER fuel when subjected to fast high temperature transients were initiated at LASL in $1960^{(1)}$. Using a 3.5 megawatt power supply, 15 inch lengths of KIWI B-1 fuel were electrically heated to different power levels for several transient times. The shortest time within which samples were fragmented was 1.5 to 2 seconds. It was found that air stored fuel could be fragmented into small pieces when approximately $2100 \mathrm{cal} / \mathrm{gram}$ of energy was deposited in the sample while freshly carbided elements burned in two whenever energies in excess of $2400 \mathrm{cal} / \mathrm{gram}$ were used. The results inferred that the primary mechanism for fragmentation was the rapid conversion of $\mathrm{UO}_{2}$ to $U \mathrm{C}_{2}$ and the attendant release of $\mathrm{CO}$. Since these tests were performed on admixture

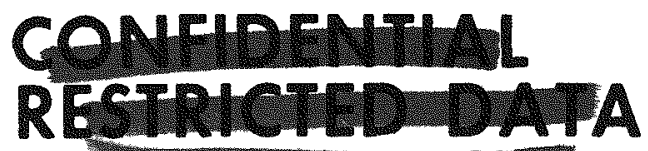


fuel as opposed to the new beaded particle fuel, where beads of $\mathrm{UC}_{2}$ are coated with pyrolytic carbon, the results on the energy required to cause fragmentation are only of qualitative value.

In September 1961, a joint LASL, Argonne National Laboratory and WANL program was undertaken to study the behavior of KIWI B-4 type fuel pulsed in the TREAT reactor (2), (3). Fuel fragmentation thresholds were estimated from these experiments to be approximately $1200 \mathrm{cal} / \mathrm{gm}$ for air stored fuel and $2900 \mathrm{cal} / \mathrm{gm}$ for fully carbided fuel. Both the air stored and fully carbided elements were admixture types of fuel and the total transient time for energy deposition into these samples was of the order of 1 second.

TREAT experiments on the new beaded particle fuel have been performed during the past contract year and the results and conclusions drawn were:

a. No fragmentation occurs even with a total weight loss of over $20 \%$.

b. High speed movies taken of the samples during the larger transients showed some of the surface fuel beads flying off like sparklers.

c. Photomicrographs of samples from larger transients showed complete disappearance of the beads with the distinct appearance of minute $U_{2}$ particles surrounding cavities in the graphite matrix.

Thus, the beaded particle fuel may, in fact, be dependent upon a non-uniform energy deposition as the primary mechanism for fuel fragmentation. In spite of the inherent 


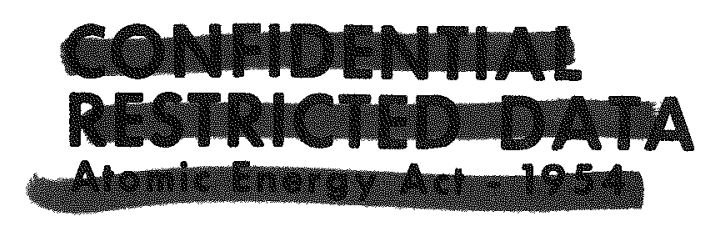

Linstronuclear

WANL-TME-531

advantage of investigating nuclear transients with the TREAT reactor, there are several limitations to the TREAT approach: the obvious cumbersomeness of any radiation problem, the limitation of transient times, the difficulty of correlating effective sample energy input with sample temperature and physical effect, the degree of instrumentation, the maximum sample size and the possibility of secondary effects resulting during the time interval between testing and evaluating the results.

In view of the results and limitations of the above experimental programs, it was decided to extend the electrical heating tests to obtain better information on the threshold energies required to cause vaporization, fragmentation and surface degradation of NERVA fuel in time intervals of 16 to $100 \mathrm{msec}$. These tests were planned to run concurrently with the remainder of the TREAT program. By comparing the electrical heating results with the conclusions from the TREAT experiments, the advantages of each method of testing can be utilized to enhance the overall understanding of conditions during reactor excursions, nuclear destruct and start-up.

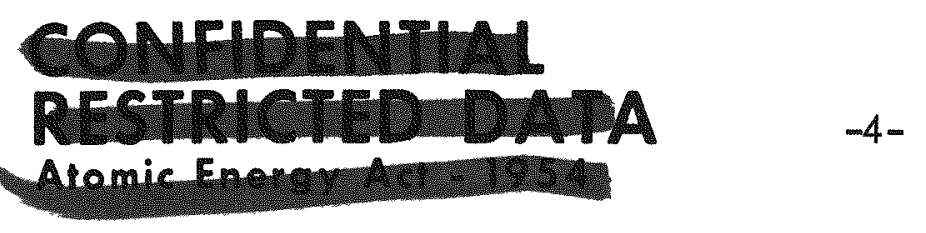




\section{DESCRIPTION OF EXPERIMENTS}

\section{A. Experimental Equipment}

The equipment used in these experiments, were essentially, a sample support and electrode assembly, an AC power supply and circuit breakers, and auxilliary monitoring equipment.

The sample support assembly consisted of two copper electrodes in the form of ring clamps, bolted to a $16^{\prime \prime} \times 6^{\prime \prime} \times 3 / 4^{\prime \prime}$ Micarta board. The ring clamps had a hexagonal internal configuration with dimensions appropriate for maintaining close contact on all six faces of a NERVA fuel geometry graphite segment. This clamping arrangement secured the test sample without obstructing the ends allowing free exit of any graphite vapor formed. Figure 1 shows the sample support assembly contained in a $9 " \times 10^{\prime \prime} \times 24^{\prime \prime}$ long pyrex pipe enclosure.

Power was supplied by a 100,000 amp, 600 volt AC generator at the Westinghouse East Pittsburgh High Power Engineering Laboratory. Two pneumatically driven synchronized circuit breakers were used to initiate and terminate the electrical pulse. These circuit breakers can be set to obtain a minimum of a quarter of a cycle of the generator which is a pulse duration of 4.2 milliseconds.

The current, voltage, power and temperature were monitored on a 12 channel Siemans Halske Oscilloscope Model 5T. The current was measured with a 15,000/5 ratio Westinghouse current transformer (Model 92R567) while the voltage was measured with a $600 / 120$ ratio Westinghouse P.T. voltmeter. The power delivered to the test sample was measured by feeding the output of two current transformers (same as above), to a $25 / 5$ ratio

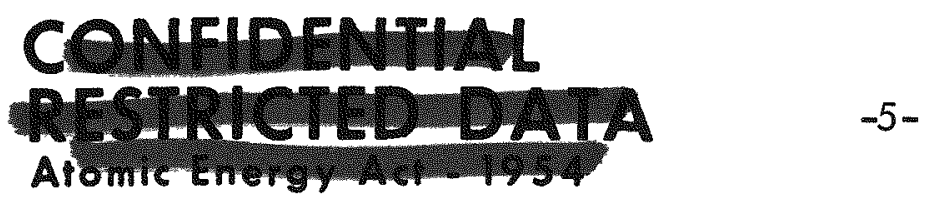




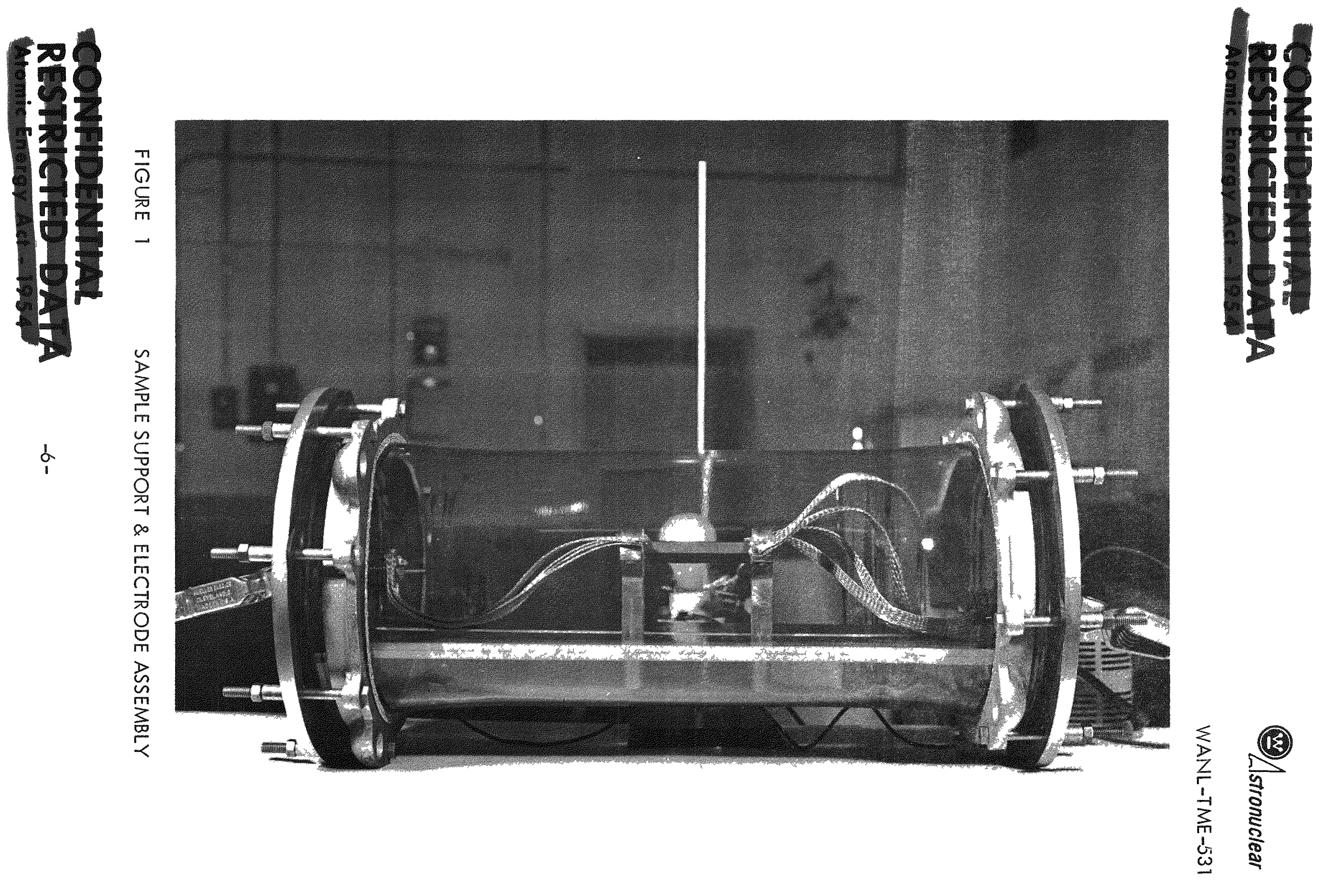




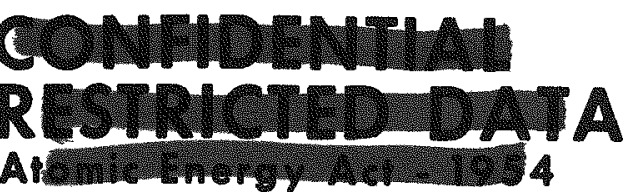

Weston Wattmeter Model 461. Temperatures were measured with a remote reading Thermoscope optical pyrometer (Milletron, Inc.) which had a range of $1500-3500^{\circ} \mathrm{C}$. The salient features of the apparatus are shown pictorially in Figure 2, and schematically in Figure 3.

\section{B. Model Specifications}

For this initial feasibility study, it was decided to use graphite as a test material, rather than fueled graphite with its attendant radiological hazard. Studies by previous investigators $(1),(2),(3)$ indicated that energies in the order of 2000 calories per gram were required to fragment or vaporize the fueled graphite which appeared to be a reasonable criterion to apply to the unfueled graphite. In order to achieve this energy during 16 millisecond transients with our $6 \times 10^{7}$ watt power supply, it was necessary to use test samples with a maximum weight of 120 grams. This weight corresponds to approximately an eleven inch segment of a graphite rod with NERVA fuel geometry. For all of the tests, a 7.5 inch segment of graphite rod was used which gave us $33 \%$ excess available energy; i.e., a total of 2,660 cals/gram maximum available energy.

\section{Experimental Procedure}

Graphite samples $7.5^{\prime \prime}$ long were copper plated at the ends, to reduce contact resistance between the graphite and the copper electrodes. The copper plate was 1 mil thick and covered a portion of the graphite up to a distance of $1.5^{\prime \prime}$ from either end, leaving an exposed central section of the graphite test piece $4.5^{\prime \prime}$ long. The test specimen was clamped in the electrode support assembly, and the resistance determined in situ. For these initial experimental, the tests were made in air, without containing the support assembly in the pyrex enclosure. Future tests on fueled material will be run in the pyrex

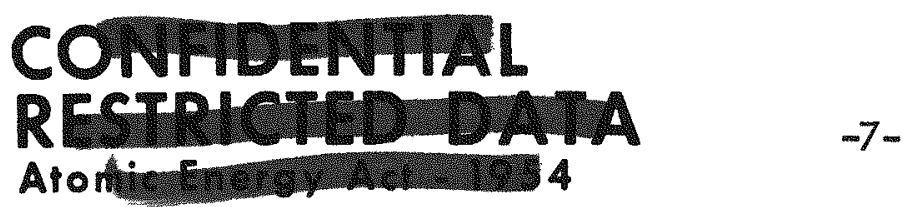





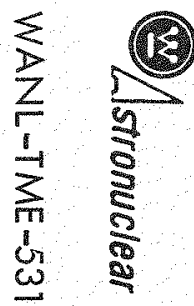




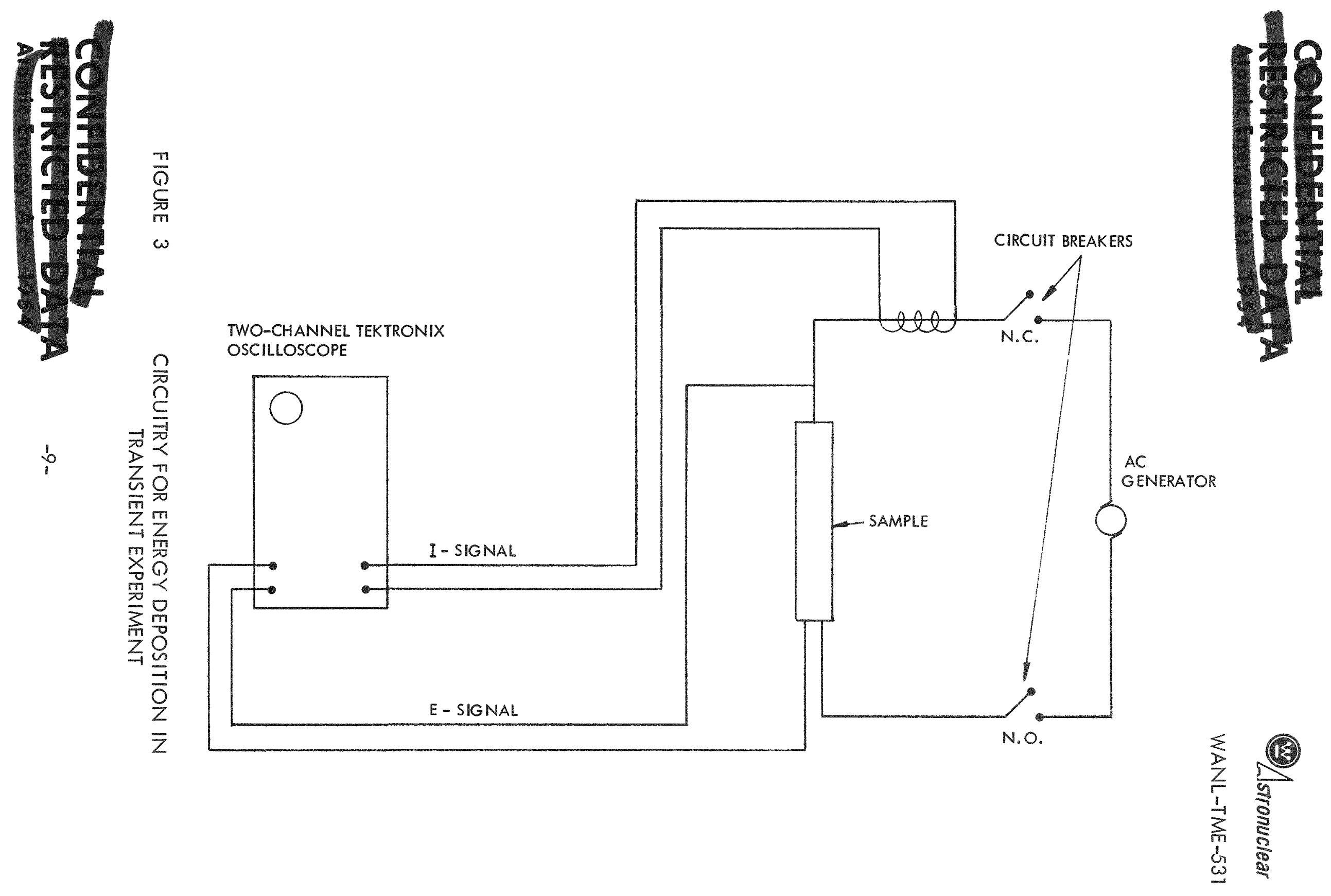



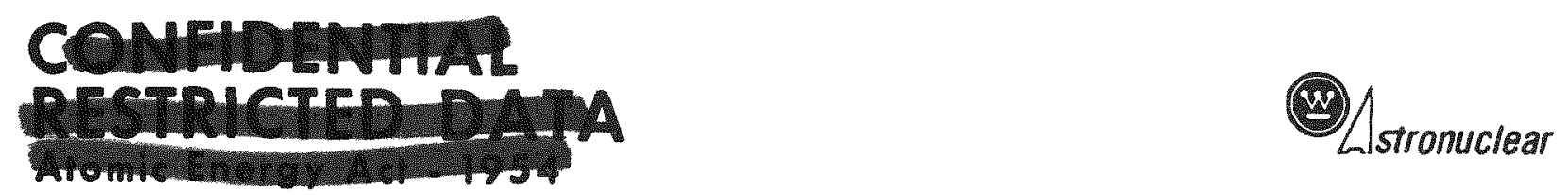

WANL-TME -531

tube under controlled atmospheres.

A bias was imposed on the thermoscope by means of a 500 watt light bulb located behind the test specimen, and in line of sight with the thermoscope lens. This bias, set at some temperature below the anticipated sample temperature, served to decrease the inherent lag time of the thermoscope response in an attempt to make this response compatible with a 16 millisecond transient.

A Fastax camera, synchronized to lead the initial circuit breakers by several msec, was used to provide a photographic record of the test. These high speed movies recorded the flash of a photographic flash bulb which was fired coincident with the initiation of the transient. A timing disc rotating at 13.3 revolutions a second provided a time reference with which to analyze events during the transient.

Signals from the current transformer, voltmeter and thermoscope were fed to the oscilloscope, which had provision for photographing the various traces. These photom graphs provided a permanent record of the various measured parameters and pe mitted determination of the voltage, current, power ${ }^{\prime}$ and temperature received by the sample $e_{y}$ as well as the duration of the transient time.

\section{Reduction of Data}

Figure 4 shows a typical oscilloscope trace obtained during a test run.

Calibration values to apply to the amplitude of the various traces, voltage "current, power and temperature, were obtained prior to each test. In order to determine the power level achieved during a transient, the total area under the power trcce was determined by integration with a polar planimeter. This area in square inches when divided by the length

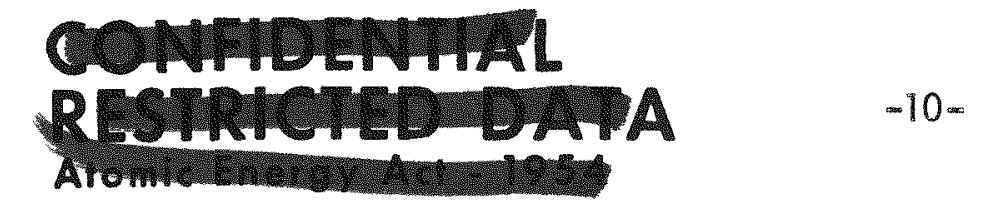




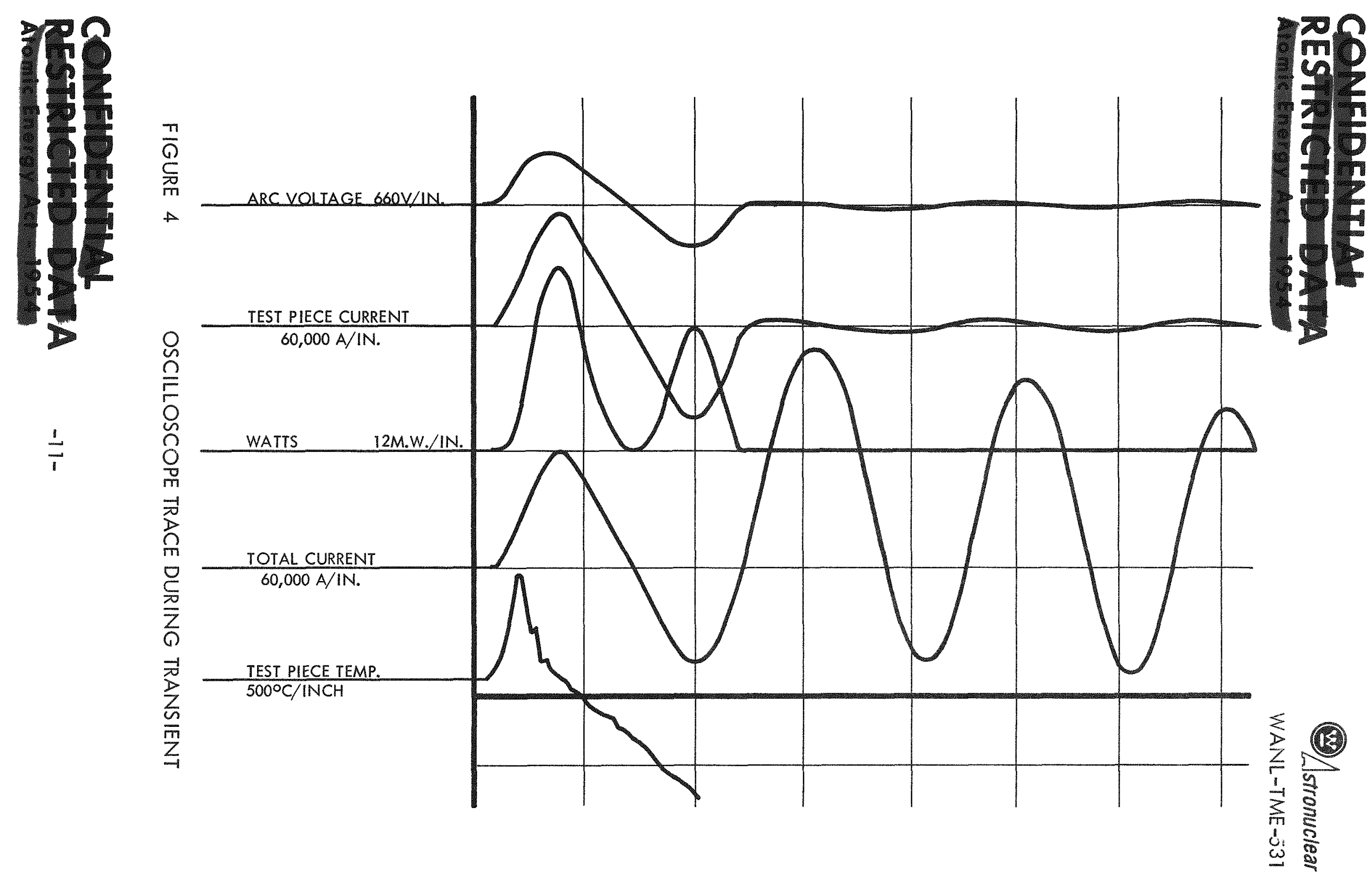




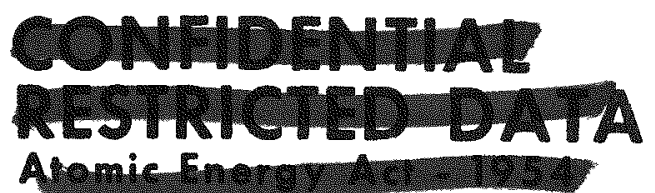

of the abscissa in inches, gave the power level in inches, which could be converted to watts by the calibration factor.

The energy delivered to the sample can now be determined by the product of watts and transient duration. The transient duration is easily determined by observing the number and/or fractional portion of a.c. cycles which comprised the test run, each full cycle being equal to 16.7 mill iseconds.

The current and voltage during the transient was determined in a similar manner, however, these parameters were not routinely calculated, rather spot checks were made to see if these values corresponded to the measured power.

The temperature traces were disappointing, since in all runs they were erratic and inconsistent. For the majority of the runs, one large peak apparently corresponding to the peak temperature was obtained. This trace, however, was deflected downscale in approximately 3 to 4 milliseconds, which is not consistent with post mortem examination of the test with high speed movies.

Typical events, during a transient in which the sample disintegrated, are shown in the sequence of high speed photographs shown in Figure 5. 

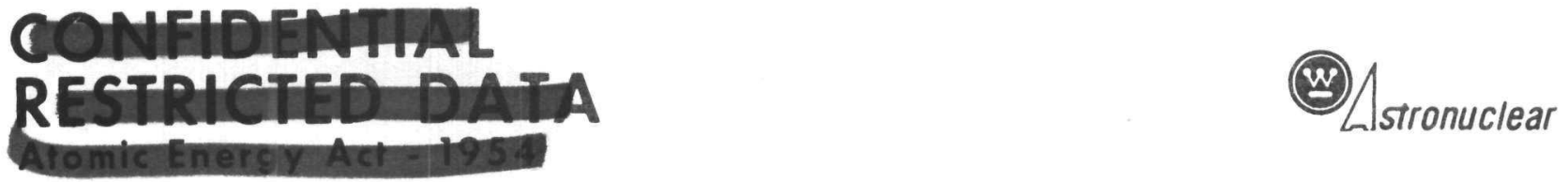

WANL-TME-531
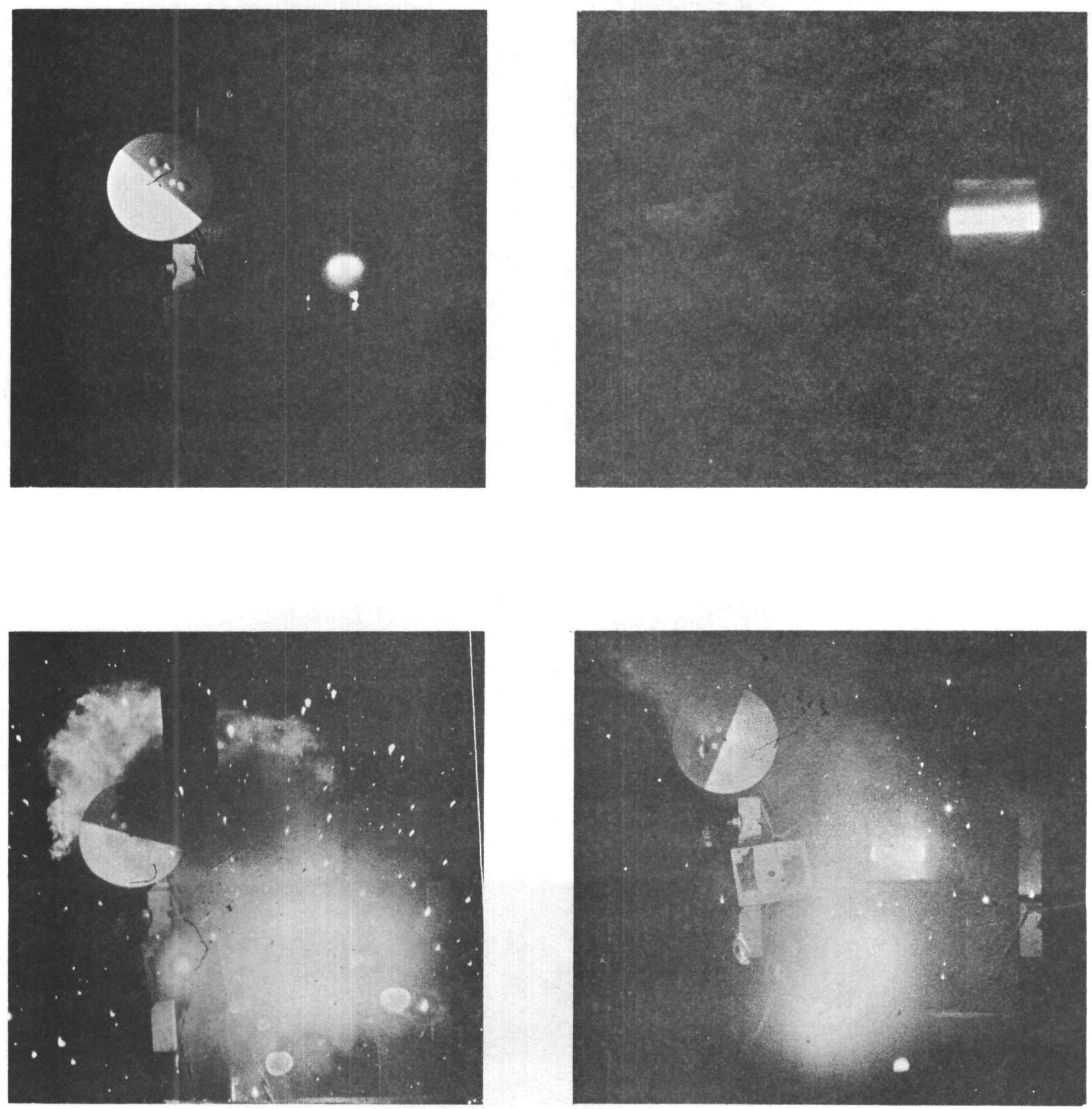

\section{FIGURE 5}

FRAGMENTATION OF GRAPHITE DURIN 316

MILLISECOND TRANSIENT AT 2000 CALS/GM

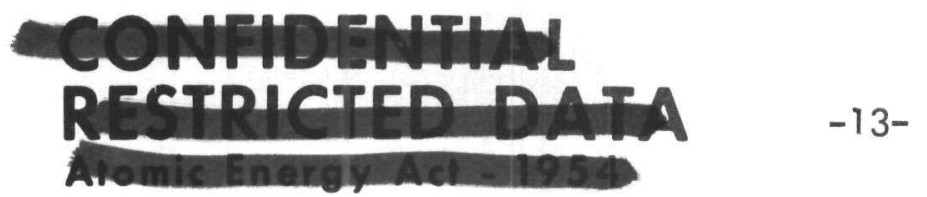




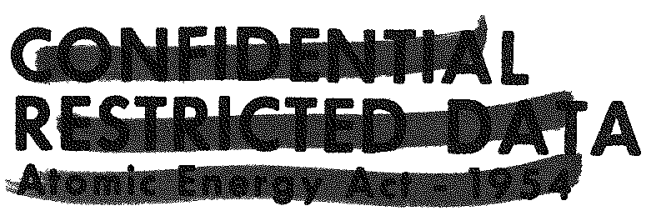

\section{DISCUSSION OF RESULTS}

\section{A. Energy Losses}

In order to determine the net energy which was deposited into the sample, the relative effects of the following potential losses need to be investigated.

a. thermal radiation losses,

b. losses due to arcing and contact resistance, and

c. thermal conduction losses.

The energy losses during a typical transient due to radiation were calculated by the relationship:

$$
1=6 \sigma \mathrm{AET}^{4}
$$

where:

$$
\begin{aligned}
& 1=\text { heat loss (calories) } \\
& \epsilon=\text { emissivity }=0.8 \text { for graphite } \\
& \sigma=\text { Stefan-Boltzmann constant }=1.36 \times 10^{-2}\left(\text { cals } / \mathrm{sec}-\mathrm{cm}^{2}\right) \\
& t=\text { time in seconds }=16 . \times 10^{-3}(\text { seconds) } \\
& A=\text { surface area }=60 .\left(\mathrm{cm}^{2}\right) \\
& T=\text { temperature }\left({ }^{\circ} \mathrm{K}\right)
\end{aligned}
$$

Assuming the maximum temperature in the tests will be limited to that given by sublimation (approximately $4000^{\circ} \mathrm{K}$ ) and that this is a steady state temperature rather than a transient

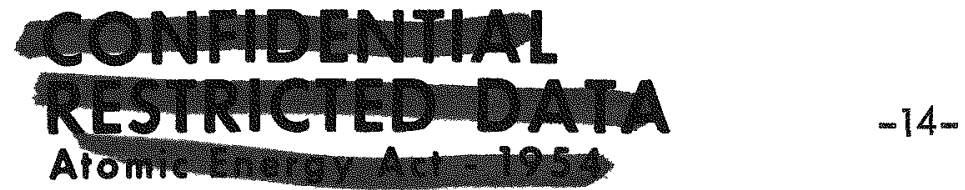




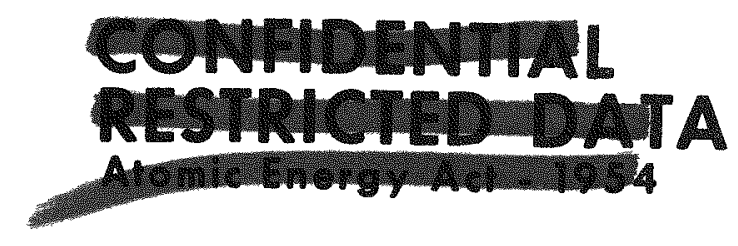

heating to this value, the radiation heat loss during the energy deposition will be about $5.5 \mathrm{cal} / \mathrm{gm}$. The total caloric input during the transient required to reach the sublimation temperature is approximately $1800 \mathrm{cal} / \mathrm{gm}$. Thus, the radiation heat losses constituted less than $0.3 \%$ of the total energy deposition for a typical transient of 16 milliseconds. For a few of the transients, the pulses were about 100 milliseconds in length and the energy losses during these pulses due to thermal radiation were less than $2 \%$ of the total energy input to the sample.

Energy losses due to arcing and contact resistance were also considered. Arcing between the specimen electrodes was not anticipated because of the low voltage involved (less than 300 volts). Mean values of the contact resistance were determined by a series of calibration experiments. These were incorporated into the evaluation of the effective length and mass of the sample to which the energy was deposited. The energy losses due to contact resistance, based upon the sample and contact resistances at room temperature, were less than $6 \%$ of the total input to the sample. In the determination of the energy deposited into the effective mass of the sample, this contact resistance loss was subtracted from the total.

In order to find the magnitude of the heat losses due to thermal conduction to the copper electrodes, three tests were made in which a standard graphite specimen was heated with a 20 KVA power supply. An energy input of 0.22 megawatt seconds was deposited in each of the samples for various elapsed times and power levels. The following table lists the power level, elapsed time and maximum recorded temperature for these three samples. 


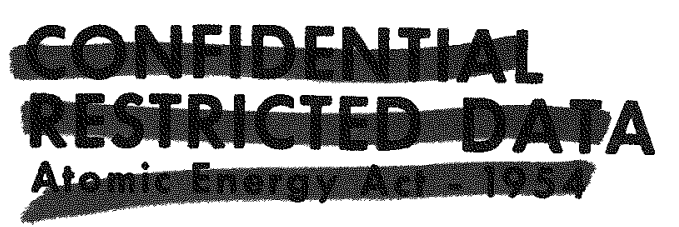

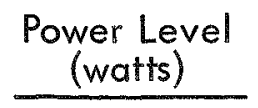

1628

2280

$$
\begin{aligned}
& \text { Elapsed Time } \\
& \text { (seconds) }
\end{aligned}
$$

135

96

84
Maximum Sample Temp.

( $\left.{ }^{\circ} \mathrm{C}\right)$

630

760

2600

1040

The energy input per unit total weight was calculated to be $630 \mathrm{cal} / \mathrm{gm}$. This corresponded to an adiabatic increase in sample temperature, as given by the change in enthalpy, to $1560^{\circ} \mathrm{C}$. It is evident that there is a trend toward closer agreement between the temperatures recorded and the adiabatic temperature with decreasing time. Extrapolation of a preliminary curve of temperature achieved versus elapsed time for a constant value of energy input indicated that the theoretical temperature would have been reached if sufficient power were applied in less than a few seconds. On this basis, it would appear that conduction heat losses to the electrodes were negligible during the 16 mill isecond transient intervals of the high power tests.

In view of the fact that the high power test results were analyzed in terms of the effective mass of the sample to which the energy was deposited, another potential conduction loss exists. This conduction path is from the resistance heated mass of the sample (approximately $49 \mathrm{gms}$ of a sample which has a total mass of $84 \mathrm{gm}$ ) to the sample ends around which the electrodes are clamped. Future analysis and/or experiments will be required to evaluate these conduction losses within the sample. It has been assumed at this point that this effect is negligible for transients on the order of 16 mill isecond. 
Axial conduction losses with in the sample will probably be significant in the longer transients tests (100 millisecond), thereby decreasing the effective energy deposition per unit mass.

\section{B. Effects of Energy Deposition}

The primary objective of this experimental program is to determine the physical effects of depositing various amounts of energy into a fuel element sample for various transient times. The effective energy per unit mass given to the sample can be evaluated from the results of the integration of the transient power curve and the calculation of the effective mass of the sample which was electrically heated. The physical effects which resulted from these energy depositions were observed visually as well as photographically.

A series of calibration experiments were performed to determine the electrical resistivity of the graphite samples. Noting that the portion of the sample through which the current passed was also that portion of the sample which was heated up during the high power fast transients, the effective length and in turn, the effective mass of the sample which received the energy was calculated from measured resistance. Due to the design requirements for the electrodes, the effective mass of the sample was considerably less than the total mass (about $49 \mathrm{gms}$ as opposed to $84 \mathrm{gms}$ ).

The total integrated power was divided by the effective mass to give the net energy deposited to each sample. Shown in Table I are the results of the first series of electrical heating experiments, including the test number, average power, elapsed time of transient, energy deposited per unit mass and adiabatic temperature. Since the energy per unit mass represented a change in enthalpy in cal/gm, an adiabatic temperature was also calculated. When the enthalpy change exceeded that required to raise it to the 


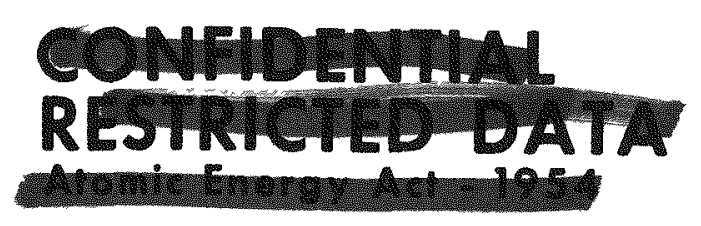

sublimation temperature, sublimation and/or oxidation probably occurred. In this case, the sublimation temperature $\left(-3700^{\circ} \mathrm{C}\right)$ was assumed. Unfortunately, experimental measurements of the peak sample temperature during the transient were not possible with the optical pyrometer. Possible causes of the erratic temperatures recorded were lack of fast response time, intermittent clouds of black smoke, exothermic reaction of oxidation and radiation from cyanogen gas formed at these temperatures.

From Table I, it may be noted that four of the samples tested (tests I, L, V, and $Y$ ) received effective energies per unit mass greater than the change in enthalpy, (approximately $1800 \mathrm{cal} / \mathrm{gm}$ ) required to raise them to the sublimation temperature. From the visual and photographic observation of each of these four tests, it was apparent that considerable sublimation, fragmentation and/or oxidation took place, especially on the extremely fast transient tests. On the two slower transients, tests $I$ and $L$, thermal conduction losses from the effective mass to the ends of the sample probably contributed to inhibiting these phenomena. 
TABLE I

RESULTS OF THE FIRST SERIES OF ELECTRICAL HEATING EXPERIMENTS

\begin{tabular}{|c|c|c|c|c|c|}
\hline Test & $\begin{array}{l}\text { Average } \\
\text { Current } \\
\text { (amps) } \\
\end{array}$ & $\begin{array}{l}\text { Average } \\
\text { Power } \\
\text { (MW) } \\
\end{array}$ & $\begin{array}{l}\text { Elapsed Time } \\
\text { of Transient } \\
\text { (Millisec) }\end{array}$ & $\begin{array}{l}\text { Energy Deposited } \\
\text { per Unit Mass } \\
\text { (cal/gm) }\end{array}$ & $\begin{array}{l}\text { Adiabatic } \\
\text { Temp. } \\
\left({ }^{\circ} \mathrm{C}\right) \\
\end{array}$ \\
\hline$E$ & 14,800 & 3.4 & 62. & 1090 & 2470 \\
\hline $\mathrm{H}$ & 8,400 & 0.94 & 97 & 470 & 1240 \\
\hline 1 & 15,800 & 4.0 & 96 & 1970 & 3700 \\
\hline$J$ & 15,000 & 2.05 & 104 & 1100 & 2480 \\
\hline K & 14,500 & 2.8 & 68 & 990 & 2280 \\
\hline L & 13,000 & 2.6 & 259 & 3500 & 700 \\
\hline M & 24,700 & 5.6 & 25 & 730 & 1770 \\
\hline$P$ & 25,500 & 9.5 & 33 & 1540 & 3280 \\
\hline$Q$ & 25,100 & 8.1 & 21 & 830 & 1970 \\
\hline$R$ & 22,200 & 5.8 & 21 & 590 & 1490 \\
\hline$S$ & 24,100 & 7.8 & 16 & 610 & 1530 \\
\hline T & 45,000 & 9.8 & 20 & 960 & 2220 \\
\hline$U$ & 35,600 & 11.0 & 19 & 1020 & 2340 \\
\hline V & 41,600 & 43.0 & 16 & 3350 & 3700 \\
\hline W & 33,400 & 14.0 & 17 & 1160 & 2600 \\
\hline$x$ & 41,600 & 16.0 & 17 & 1340 & 2920 \\
\hline Y & 47,400 & 18.0 & 66 & 5630 & 3700 \\
\hline
\end{tabular}




\section{CONFHOENTHAL}

RESTHETED DATA

\section{TABLE 1}

RESULTS OF THE FIRST SERIES OF ELECTRICAL HEATING EXPERIMENTS

\begin{tabular}{|c|c|c|c|c|c|}
\hline Test & $\begin{array}{l}\text { Average } \\
\text { Current } \\
\text { (amps) }\end{array}$ & $\begin{array}{l}\text { Average } \\
\text { Power } \\
\text { (MW) }\end{array}$ & $\begin{array}{l}\text { Elapsed Time } \\
\text { of Transient } \\
\text { (Millisec) }\end{array}$ & $\begin{array}{l}\text { Energy Deposited } \\
\text { per Unit Mass } \\
\text { (cal } / \mathrm{gm})\end{array}$ & $\begin{array}{l}\text { Adiabatic } \\
\text { Temp. } \\
\left({ }^{\circ} \mathrm{C}\right)\end{array}$ \\
\hline $\mathrm{AA}$ & 44,800 & 18.5 & 19 & 1730 & 3620 \\
\hline$A B$ & 57,200 & 10.5 & 20 & 1030 & 2360 \\
\hline$A C$ & 62,400 & 11.0 & 19 & 1020 & 2340 \\
\hline$A D$ & 43,100 & 12.0 & 19 & 1130 & 2540 \\
\hline $\mathrm{AH}$ & 47,500 & 19.0 & 18 & 1680 & 3530 \\
\hline AJ & 43,800 & 15.0 & 13 & 910 & 2120 \\
\hline
\end{tabular}




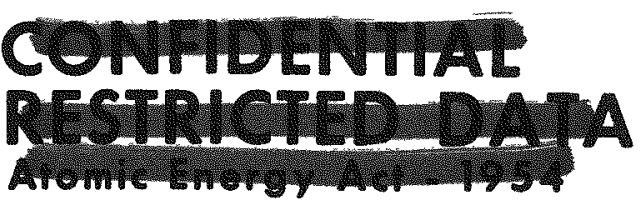

\section{CONCLUSIONS AND FUTURE PLANS}

Three general conclusions may be drawn from this preliminary study:

1. A technique has been developed for the deposition of high energies in 7.5" graphite segments of NERVA fuel geometry in times (16 msec) comparable with nuclear transients. These energies are sufficient to cause fragmentation and sublimation of the graphite specimens.

2. The energy per unit mass required to cause fragmentation and sublimation was approximately $2000 \mathrm{cals} / \mathrm{gm}$. Energies of $1700 \mathrm{cals} / \mathrm{gram}$ or less do not fragment the sample.

3. The data obtained from these tests should be capable of being compared with the TREAT resul ts and future TRIGA experiments.

Future plans for this program will include:

1. A continuation of the effort to develop a method of measuring the sample temperature during a fast transient.

2. A more accurate determination of the vaporization and fragmentation threshold energies.

3. A study of the effects of various environments (He vacuum) on mass losses due to sublimation and fragmentation.

4. A study on the amount of down channel deposition of carbon and uranium as a result of sublimation. 
5. Having determined the sublimation and fragmentation

threshold energies for unfueled graphite elements, a similar series of tests for fueled graphite elements will be performed. 


\section{REFERENCES}

1. King, L.D.P., and Stratton, W. R., "The Response of KIWI Reactors to Abnormal Reactivity Insertions - Preliminary Appendix B: RIFT Safety Review, " RFS-135, Los Alamos Scientific Laboratory, January, 1963 $(C-R D)$.

2. Boltax, A., "Transient Reactor Experiments on NERVA Fuel Material," WANL-TNR -038, March, 1962 (C-RD).

3. Ivins, R.O., et al, "Status Report II on the Testing of Graphite -Type Nuclear Rocket (ROVER) Fuel in a Pulsed Reactor (TREAT), ANL -6572 January, 1963 (C-RD). 